\title{
Comparação entre as abordagens ecológica e cognitivista para o treino da tomada de decisão no Ténis e no Rugby
}

\author{
Pedro Passos \\ Rui Batalau \\ Pedro Gonçalves
}

https://doi.org/10.5628/rpcd.06.03.305

\section{RESUMO}

Em qualquer modalidade desportiva a tomada de decisão é uma variável que condiciona a consistência de desempenhos de sucesso. Os dois estudos de carácter longitudinal aqui apresentados têm como objectivo determinar a existência de diferenças na evolução no desempenho das seguintes tarefas - a placagem no Rugby e o primeiro serviço no Ténis - como resultado da adopção de metodologias sustentadas por diferentes abordagens para treino da tomada de decisão: i) a abordagem cognitivista, a qual assenta na procura de um modelo ideal de execução, e ii) a abordagem ecológica, baseada na manipulação dos constrangimentos visando que o atleta encontre o seu próprio padrão de execução. Com base nos resultados da análise de estabilidade e comparações intra e inter-grupo, podemos concluir que a abordagem baseada nos constrangimentos se apresenta como a metodologia mais eficaz para o treino da tomada de decisão. A nossa interpretação sugere que a procura de modelos ideiais de execução, resulta em prescrições de treino desajustadas às características dos jogadores, o que faz com que existam grandes oscilações nos seus desempenhos e que um treino baseado na manipulação dos constrangimentos permite ao atleta adaptar as suas características às exigências do envolvimento, numa exploração activa do melhor caminho para alcançar um objectivo.

\author{
Universidade Lusófona de H umanidades e Tecnologias \\ Lisboa \\ Portugal
}

\section{ABSTRACT \\ A comparison between ecological and cognitive approach to decision-making training in tennis and rugby}

On every sport decision-making is variable that influence the stability of successful performances. This two studies aim to set the existence of differences on the evolution of performance of the following tasks tackle in Rugby and the first serve on Tennis - as a result of the adoption of two methodologies sustained by different approaches to decision making training: i) a cognitive approach, which is sustain by ideal models of performance, and ii) an ecological approach, sustain by constraints manipulation. Based on the results of stability analysis and intra and inter-group comparison we can conclude that the constraints based approach was a better methodology to the training of decision making. O ur discussion suggest that a decision making training based on a cognitive approach result on performance prescriptions that does$n$ 't fit on the players individual characteristics, resulting on wide performance fluctuations. $\mathrm{On}$ the other side the constraints based approach allows the athlete to adapt his individual characteristics to the environment demands, on active searching of the better path to achieve a goal.

Key-words: decision-making, rugby, tennis

Palavras-chave: tomada de decisão, rugby, ténis. 


\section{INTRODUÇÃO}

Durante décadas, a compreensão dos processos envolvidos na coordenação do movimento, controlo e aquisição de técnicas, tem sido um desafio para os investigadores do comportamento motor. Este problema tem confrontado diferentes concepções de análise do movimento e controlo motor que são segundo Davids, Williams, Button e Court (1), por um lado, a teoria ou ciência cognitiva clássica e, por outro, um conjunto de teorias interrelacionadas como a Teoria dos Sistemas Dinâmicos, a Psicologia Ecológica e a Coordenação Dinâmica que formam a abordagem ecológica.

\section{A abordagem cognitivista}

$\mathrm{Na}$ abordagem cognitivista assente na teoria computacional ou do processamento de informação, considera-se que a tomada de decisão e a acção são determinadas pela comparação entre a informação que chega pelos orgãos sensoriais (p.ex. o sistema visual) e a informação armazenada em memória sob forma de representações mentais (i.e. representações simbólicas da realidade) (2). A base teórica das considerações em psicologia cognitiva sobre a coordenação e controlo do movimento assentam numa analogia entre a mente humana como um computador capaz de formar representações simbólicas no sistema nervoso central, durante um comportamento di reccionado para o objectivo (1). Ou seja, de acordo com as teorias do processamento de informação, a acção coordenada de determinado gesto técnico assenta numa relação entre estímulo-resposta, previamente definida e armazenada em memória. Pelos pressupostos da abordagem cognitivista o treino deve assentar na construção de representações mentais que sustentem a relação entre estímulo e resposta. Para tal, o treinador deve descrever ao atleta com base num modelo ideal de execução quais as principais componentes críticas de uma tarefa ( $p . e x$. como executar uma placagem no Rugby, ou como realizar um primeiro serviço no Ténis), uma vez que se considera que este tipo de instrução contribui para o desenvolvimento do conhecimento cognitivo a partir do qual as capacidades perceptivas se desenvolvem (3).

A intervenção do treinador centra-se predominantemente nos atletas e na forma como estes realizam a acção proposta, menosprezando a influência das con- dições da tarefa e do envolvimento (4). Ao considerar a importância das representações mentais, torna-se fundamental que o treinador prescreva um modelo de execução considerado ideal, de modo a induzir nos atletas uma noção clara do esquema de acção que se pretende que seja interiorizado.

Deste modo, a demonstração, a instrução e a informação de retorno utilizadas de forma prescritiva sobre as execuções, são fundamentais para a aprendizagem dos movimentos considerados correctos. Isto porque é necessário incentivar os atletas a pensarem como executam os movimentos prescritos, comparando o seu desempenho e o referido modelo ideal, de forma a tomarem as decisões consideradas como ideiais e só depois agirem. A informação de retorno que sustenta o desempenho do modelo ideal de execução poderá ser feita recorrendo à observação em vídeo das execuções efectuadas de uma tarefa motora (p.ex. o primeiro serviço no Ténis), o objectivo é comparar as componentes críticas do modelo ideal de execução com a sua própria execução, esta comparação poderá sugerir ao atleta al guns benefícios para a optimização do programa motor a ser interiorizado.

\section{A abordagem ecológica}

A abordagem ecológica da acção seguindo a linha Gibsoniana assume um pressuposto de que existe uma relação mútua e recíproca entre sujeito e envolvimento (1). James Gibson apresenta o conceito de percepção directa, em que existe uma função determinante da informação percepcionada directamente do ambiente (i.e. sem recurso a estruturas intermé dias, como o processamento central que compara a informação que chega pelos mecanismos sensoriais com a informação armazenada em memória) para a coordenação e controlo motor. A percepção e a acção estabelecem uma rel ação directa e cíclica visto que são actividades mutuamente interdependentes, não podendo ser estudadas separadamente. Tal como Gibson (p.223) refere "“We must perceive in order to move, but we must also move in order to perceive." (5). Dito por outras palavras, toda a informação necessária para a acção está disponível no envolvimento e é percepcionada directamente pelo atleta, tendo este com a sua acção uma influência di recta na alteração da informação presente no envolvimento. Ou seja, 
percepcionamos a informação presente no contexto para decidirmos e agirmos, e com a nossa acção alteramos a informação do contexto para continuarmos a decidir e a agir e assim sucessivamente. Desta forma torna-se complicado definir uma hierarquia entre a decisão e acção, qual delas está primei ro? Por definição (6) "Uma acção é uma interacção funcional entre o indivíduo e o seu envolvimento com um determinado propósito" e uma decisão "mais do que dependente da capacidade do indivíduo está condicionada pelo que o contexto permite fazer" sendo a decisão(7) "um processo emergente, uma estratégia activa de procura de soluções caracterizada por sequências espaço-temporais na relação entre sujeito e envolvimento". Então todas as nossas decisões, não farão sentido quando retiradas do contexto, por exemplo, a decisão de um atacante no Rugby em alterar a sua linha de corrida, só acontece porque percepciona a posição de um defesa no seu caminho para a zona de ensaio, e ao alterar a linha de corrida, fá-lo (agindo) para percepcionar o que o defesa irá fazer (qual a sua acção), e assim sucessivamente, da mesma forma, a decisão de um jogador de Ténis em bater a bola para determinada zona do court, só acontecerá porque percepciona que o adversário dificilmente lá chegará em condições para responder com sucesso. A informação que permite cada jogador decidir e agir está disponível no envolvimento, resultando da interaç̧ão entre jogador e contexto. Como tal os problemas que se col ocam a cada jogador emergem da sua interacção com o contexto sendo, em muitos aspectos, imprevisíveis. Neste sentido, não é aconsel hável determinar à partida qual o gesto técnico que pretendemos que os nossos jogadores realizem. A informação de retorno fornecida pelo treinador (i.e. feedback pedagógico) é igualmente informação disponível no envolvimento, porém apenas fará sentido como um reforço de quais os objectivos de tarefa alcançados e a alcançar, respeitando a variabilidade da acção de cada jogador para alcançar esses objectivos. Desta forma o feedback pedagógico será passível de afinar os acoplamentos de percepção-acção, o atleta percepciona para agir no sentido de al cançar os objectivos de tarefa e age para percepcionar se está no caminho certo para os al cançar.

Partindo deste pressuposto sugerimos que existe uma grande dependência entre o que será a técnica ade- quada e as situações reais de jogo, verificando-se que determinados modelos de execução poderão estar desajustados para certas situações que o jogo impõe, visto que os desempenhos com sucesso não se caracterizam por movimentos utilizados de forma estereotipada, mas sim pela sua adequação física e temporal a cada situação, por exemplo, um jogador que toma a decisão de fazer uma finta ao seu defesa, só continuará com essa acção caso a informação que Ihe chega da acção do defesa lhe permita continuar a sua finta com sucesso, caso contrário pode perder a posse de bola. Mas a informação presente no envolvimento é detectada de acordo com os constrangi mentos que limitam o espaço onde o atleta percepciona e age, limites esses que condicionam a especificidade da acção a realizar.

\section{O modelo dos constrangimentos de Newell}

Para Karl N ewell constrangimentos são factores que permitem restringir ou constranger a dinâmica da resposta (8).

No Modelo de N ewell estão presentes três categorias de constrangi mentos que interagem para a emergência (i.e. surgimento de forma espontânea sem qualquer ordem exterior) de um padrão óptimo de coordenação de uma tarefa específica: i) os constrangimentos do sujeito, ii) os constrangimentos do envolvimento e iii) os constrangimentos da tarefa. Os primeiros, referem-se às características de cada sujeito, o peso, a altura, as qualidades físicas como a força, a resistência, a velocidade, qualidades psicológicas como as emoções, os pensamentos, ou a confiança. Os constrangimentos do envolvimento referem-se às condições de ambiente que rodeia o sujeito, são externos ao sujeito e à tarefa, mas influenciam o seu desempenho, tais como as condições do piso, o vento, a chuva, o público. Por fim os constrangimentos da tarefa, são os mais específicos, onde se incluem os objectivos individuais, as regras do jogo, a estratégia, a táctica, os limites do campo e instrumentos específicos de cada modalidade, como sejam, uma raqueta ou a forma da bola. É pertinente referir, que a manipulação de constrangimentos é al go que necessariamente todo o treinador faz, ao estabelecer, regras para cada exercício ou para situações simuladas de jogo, limites de campo, número de jogadores envolvidos em cada tarefa. 
A interacção mútua entre as três categorias de constrangimentos gera campos de informação, que sustentam a acção e a decisão do atleta fazendo emergir padrões de coordenação ( como uma finta no Rugby ou um batimento à direita no Ténis) em comportamentos direccionados para um objectivo. A questão principal é se a manipulação de constrangimentos, gera campos de informação semelhantes à informação que os atletas vão encontrar em competição. No ponto anterior abordámos a Psicologia Ecológica seguindo uma linha Gibsoniana, a qual refere a especificidade dos acoplamentos percepçãoacção, ora, caso os campos de informação gerados pela manipulação de constrangimentos se afastem do que o atleta vai encontrar em competição, corremos o risco de estar a propor uma tarefa de treino que está a afinar acoplamentos de percepção-aç̧ão para tarefas que não aquelas que o atleta vai encontrar no jogo. Por exemplo, para uma situação de 1x1 no Rugby, caso se solicite ao defesa que tenha uma atitude passiva (i.e. aproximando-se do atacante a velocidade reduzida, indo ao contacto com pouca intensidade) estamos a manipular um constrangimento (i.e. acção de defesa) que gera campos de informação que não são os encontrados em competição. Para esta situação o atacante irá afinar os acoplamentos de percepção-acção em função de uma informação sustentada numa atitude passiva do seu opositor. Ou seja, o atacante estará treinado para resolver situações em que o defesa tenha uma atitude passiva, e não para situações em que os defesas procurem o contacto de forma intensa, tal como num jogo.

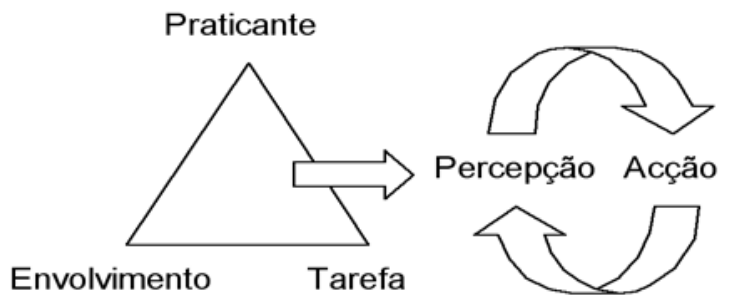

Figura 1. Modelo dos Constrangimentos de Newell

O problema

No Rugby actual a defesa assume um papel de extrema importância, sendo como tal sugerido por alguns treinadores, que $50 \%$ do treino seja dedicado ao sector defensivo, em termos individuais e colectivos(9). Neste âmbito a placagem assume um papel primordial ao ser a única situação permitida pelas leis do jogo para parar a progressão do atacante, colocandoo no chão e recuperando a posse de bola.

Em relação ao Ténis, a colocação do primeiro serviço pode ser determinante no resultado final de um jogo. Sendo nesta acção que o tenista mais arrisca em termos de potência no serviço e colocação da bola em zonas limites que criam maiores dificuldades de resposta por parte do adversário (10).

De comum, encontramos que as duas modalidades procuram a aprendizagem e desenvol vimento de gestos técnicos que podem ser determinantes para o resultado final de uma competição. De comum também encontramos que no Rugby fal ham-se placagens e no Ténis há primeiros serviços que não entram. A consistência do sucesso na placagem e no primeiro serviço será seguramente uma finalidade para os treinadores de Rugby e de Ténis. Então algumas questões se levantam: qual a melhor forma de treinar estes gestos técnicos? Seguimos os modelos ideais de execução indo ao encontro da Psicologia Cognitiva? Ou colocamos condições para que os atletas explorem e descubram o caminho para chegar ao objectivo conforme sugerido pela Psicologia Ecológica?

No sentido de dar resposta ao problema colocado, desenvolveram-se dois estudos longitudinais onde se procurou determinar a existência de diferenças na evolução no desempenho de uma tarefa - placagem e primeiro serviço - durante um mesociclo de treino, como resultado da adopção de uma abordagem cognitivista ou de uma abordagem ecológica, e para os quais uma questão mais específica se coloca: qual das metodologias correspondentes a estas abordagens será mais eficaz na evolução de desempenho dos referidos gestos técnicos?

\section{METODOLOGIA}

Para a abordagem cognitivista, a metodologia assentou na procura de um modelo ideal de execução, com recurso à instrução e ao feedback do treinador, enquanto que para a abordagem ecológica, estabeleceu-se uma metodologia baseada na manipulação de constrangimentos de tarefa. 
Para a investigação no Rugby

Participantes

Neste estudo participaram 18 jogadores de Rugby ( $n=18 ; 10$ para o grupo da abordagem cognitivista e 8 para a abordagem ecológica) dos escalões de benjamins e infantis, com idades compreendidas entre os 9 e os 12 anos. Os treinos real izam-se duas vezes por semana, durante sessenta minutos cada sessão de treino.

0 desenho de estudo

Estudo realizou-se durante cinco semanas o que faz um total de 10 sessões de treino. A recolha de dados foi feita na segunda sessão de treino de cada semana, com a excepção da primeira semana onde para efeitos de aval iação inicial se recolheram dados na primeira e na segunda sessão de treino. A recolha de dados era sempre realizada no início de cada treino, logo após o aquecimento.

\section{A tarefa}

Para o Rugby, na abordagem cognitivista a metodologia de treino assentou na procura de um modelo ideal de execução em que no início de cada sessão utilizaram-se sacos de placagem com o objectivo que os jogadores executassem correctamente as componentes críticas da placagem (componentes críticas para a execução da placagem de acordo com a Rugby Football U nion para o treino de crianças e jovens: posição corporal baixa, olhar dirigido para as coxas do adversário, impacto forte com o ombro nas coxas do portador da bola, fecho dos braços imediatamente após o contacto com o ombro e força explosiva dos membros inferiores), seguindo-se depois a realização de placagem em situação de um contra um. Ao longo de todas as sessões foi feito uso do feedback, informando o jogador em relação à forma como estava ou não a executar as componentes críticas de um suposto modelo ideal de execução da placagem. Em relação à abordagem ecológica, no Rugby a metodologia utilizada assentou na manipulação de constrangimentos de tarefa, em que apenas era transmitido ao jogador qual o objectivo pretendido (i.e impedir o adversário de marcar ensaio, em que as regras do jogo para placagem são elas próprias um constragimento de tarefa), havia uma delimitação das linhas do campo fora das quais a jogada é parada, tendo sido definida uma zona corporal onde é desejável que aconteça a placagem (i.e o jogador deve ser placado entre a cintura e os joelhos). Não foi utilizado qualquer instrumento, como os sacos de placagem, a tarefa foi sempre executada em situação de um contra um, aproximando-se mais à situação real de jogo. A informação pre sente nestes constragimentos é suficiente para que o jogador explore e descubra o melhor caminho, ou seja que se auto-organize (i.e. não necessite de qualquer ordem exterior para manter ou alterar o seu padrão de coordenação) para alcançar o seu objectivo.

Quadro 1. Desenho experimental para o Rugby.

\begin{tabular}{|c|c|}
\hline \multicolumn{2}{|c|}{ Rugby } \\
\hline Cognitivista & Ecológica \\
\hline $\begin{array}{l}\text { Em cada treino, cada jogador } \\
\text { realizava } 10 \text { placagens a cada } \\
\text { ombro com sacos de } \\
\text { placagem. } \\
\text { Para efeitos de recolha de } \\
\text { dados cada jogador realizava } \\
\text { séries de } 5 \text { situações de um } \\
\text { contra um, as quais para evitar } \\
\text { a acumulação de fadiga eram } \\
\text { não consecutivas. }\end{array}$ & $\begin{array}{l}\text { Em cada treino, cada jogador } \\
\text { realizava } 10 \text { situações de um } \\
\text { contra um. } \\
\text { Para efeitos de recolha de } \\
\text { dados cada jogador realizava } \\
\text { séries de } 5 \text { situações de um } \\
\text { contra um, as quais para } \\
\text { evitar a acumulação de fadiga } \\
\text { eram não consecutivas. }\end{array}$ \\
\hline $\begin{array}{l}\text { Foi feita uma delimitação da } \\
\text { zona do campo com as } \\
\text { dimensões de } 4 \mathrm{~m} \times 10 \mathrm{~m} \text {. } \\
\text { No ínicio de cada sessão o } \\
\text { treinador demonstrava a } \\
\text { tarefa a realizar.A instrução } \\
\text { inicial era direccionada às } \\
\text { componentes críticas.A } \\
\text { informação de retorno era } \\
\text { direccionada às componentes } \\
\text { críticas. }\end{array}$ & $\begin{array}{l}\text { Foi feita uma delimitação da } \\
\text { zona do campo com as } \\
\text { dimensões } 4 \mathrm{~m} \times 10 \mathrm{~m} \text {. } \\
\mathrm{Na} \text { instrução inicial o } \\
\text { treinador reforçava quais o } \\
\text { limites da zona corporal de } \\
\text { contacto no jogador } \\
\text { adversário. } \\
\text { Os objectivos da tarefa eram } \\
\text { reforçados. }\end{array}$ \\
\hline \multicolumn{2}{|c|}{$\begin{array}{l}\text { A recolha de dados consistia no registo numa grelha de } \\
\text { obeservação, do número de placagens que cada jogador } \\
\text { realizava. Apenas serviam para efeitos de registo as placagens } \\
\text { em que o atacante não conseguia marcar ensaio. }\end{array}$} \\
\hline
\end{tabular}

Para a investigação no Ténis

Participantes

Neste estudo participaram dez jogadores de Ténis ( $n=10$; cinco para cada abordagem) dos escalões de iniciados, infantis e cadetes, estando as suas idades compreendidas entre os 10 e os 14 anos. Os treinos realizam-se três vezes por semana, em que cada sessão tem noventa minutos. 
0 desenho de estudo

Estudo realizou-se durante três semanas o que faz um total de nove sessões de treino. A recolha de dados foi feita em todas as sessões de treino durante as três semanas. A recolha de dados era sempre real izada no início de cada treino, logo após o aquecimento.

\section{A tarefa}

$\mathrm{Na}$ abordagem cognitivista para o Ténis foi inicialmente utilizada a demonstração, focando nas principais componentes críticas contempladas num modelo ideal de execução para o primeiro serviço no Ténis. Durante as séries, o treinador tinha liberdade para recorrer ao feedback pedagógico de forma a aproximar a execução dos jogadores ao modelo. Para que os próprios jogadores pudessem comparar a sua exe cução com o desejável modelo, todas as suas execuções foram filmadas para posterior observação.

Para a abordagem ecológica em relação ao Ténis foi utilizada uma metodol ogia semelhante ao Rugby, a manipulação dos constrangimentos de tarefa consistiu na delimitação da zona onde a bola devia entrar no primeiro serviço. O treinador informou os jogadores do objectivo da tarefa (i.e. ao primeiro serviço colocar a bola o maior número de vezes dentro da zona definida), após a real ização de cada série de dez serviços cada jogador era informado do seu desempenho. À semelhança do Rugby, o único feedback exterior que o jogador recebia, era se a bola entrava ou não na zona previamente definida. A forma como cada jogador se organiza para cumprir a sua tarefa com sucesso, assenta numa descoberta individual de como realizar o primeiro serviço. $\mathrm{O}$ quadro 2 , mostra as diferenças na construção de um exercício com base nas abordagens cognitivista ou ecológica.
Quadro 2. Desenho experimental para o Ténis.

\begin{tabular}{|c|c|}
\hline \multicolumn{2}{|c|}{ Ténis } \\
\hline Cogn & Ecológica \\
\hline \multicolumn{2}{|c|}{$\begin{array}{l}\text { Em cada sessão de treino cada jogador realizava } \\
\text { de } 10 \text { serviços }\left(1^{\circ} \text { serviço], de forma a evitar os efeitos }\right. \\
\text { cumulação de fadiga as séries eram não consecutivas. }\end{array}$} \\
\hline $\begin{array}{l}\text { Foi feita uma delimitação da } \\
\text { zona do campo onde era } \\
\text { suposto o jogador colocar a } \\
\text { bola com o primeiro serviço. } \\
\text { No ínicio de cada sessão o } \\
\text { treinador demonstrava a } \\
\text { tarefa a realizar. } \\
\text { A instrução inicial era } \\
\text { direccionada às } \\
\text { componentes críticas. } \\
\text { A informação de retorno era } \\
\text { direccionada às } \\
\text { componentes críticas. } \\
\text { Todas as execuções eram } \\
\text { gravadas em video. A análise } \\
\text { dos vídeos era feita entre } \\
\text { séries. }\end{array}$ & $\begin{array}{l}\text { Objectivos: no primeiro } \\
\text { serviço, colocar a bola na zona } \\
\text { do campo previamente } \\
\text { delimitada. } \\
\text { Delimitação da zona do } \\
\text { campo. } \\
\text { Informação do sucesso do } \\
\text { desempenho. Foi feita uma } \\
\text { delimitação da zona do campo } \\
\text { onde era suposto o jogador } \\
\text { colocar a bola com o primeiro } \\
\text { serviço. } \\
\text { Na instrução inicial o treinador } \\
\text { informava e/ou reforçava } \\
\text { quais os objectivos da tarefa. }\end{array}$ \\
\hline $\begin{array}{r}\text { ção dos primeir } \\
\text { previa }\end{array}$ & $\begin{array}{l}\text { registo numa grelha de } \\
\text { os que entravam na zona } \\
\text { efinida. }\end{array}$ \\
\hline
\end{tabular}

\section{RESULTADOS}

A análise gráfica foi construída com base nos valores de média e desvio-padrão de todos os participantes em cada sessão. Para ambos os estudos, embora seja possível observar uma variação das curvas ao longo do tempo, a qual indica que houve evolução no desempenho, a análise gráfica não permite identificar, de forma clara e inequívoca, qual dos grupos (abordagem ecológica ou da abordagem cognitivista) teve a maior evolução.

Porém, ao recorremos ao valor do desvio-padrão como parâmetro de estabilidade, poderemos sugerir que existem diferenças entre os grupos no que respeita à frequência de desempenhos de qualidade. $O$ desvio-padrão indica-nos qual o grupo que apresenta maior número de resultados em torno na média. Quanto mais próximo da média mais estável é o comportamento do grupo. Pelo contrário, quanto mais afastado da média, significa que houve jogado- 
res no grupo com bons desempenhos (mais próximos dos valores máximos) enquanto que outros tiveram maus desempenhos (mais próximos dos valores mínimos), situação esta que é pouco desejável.

Legenda: A linha tracejada representa os valores da média mais o desvio-padrão. A linha ponteada representa os valores de média menos o desvio-padrão.
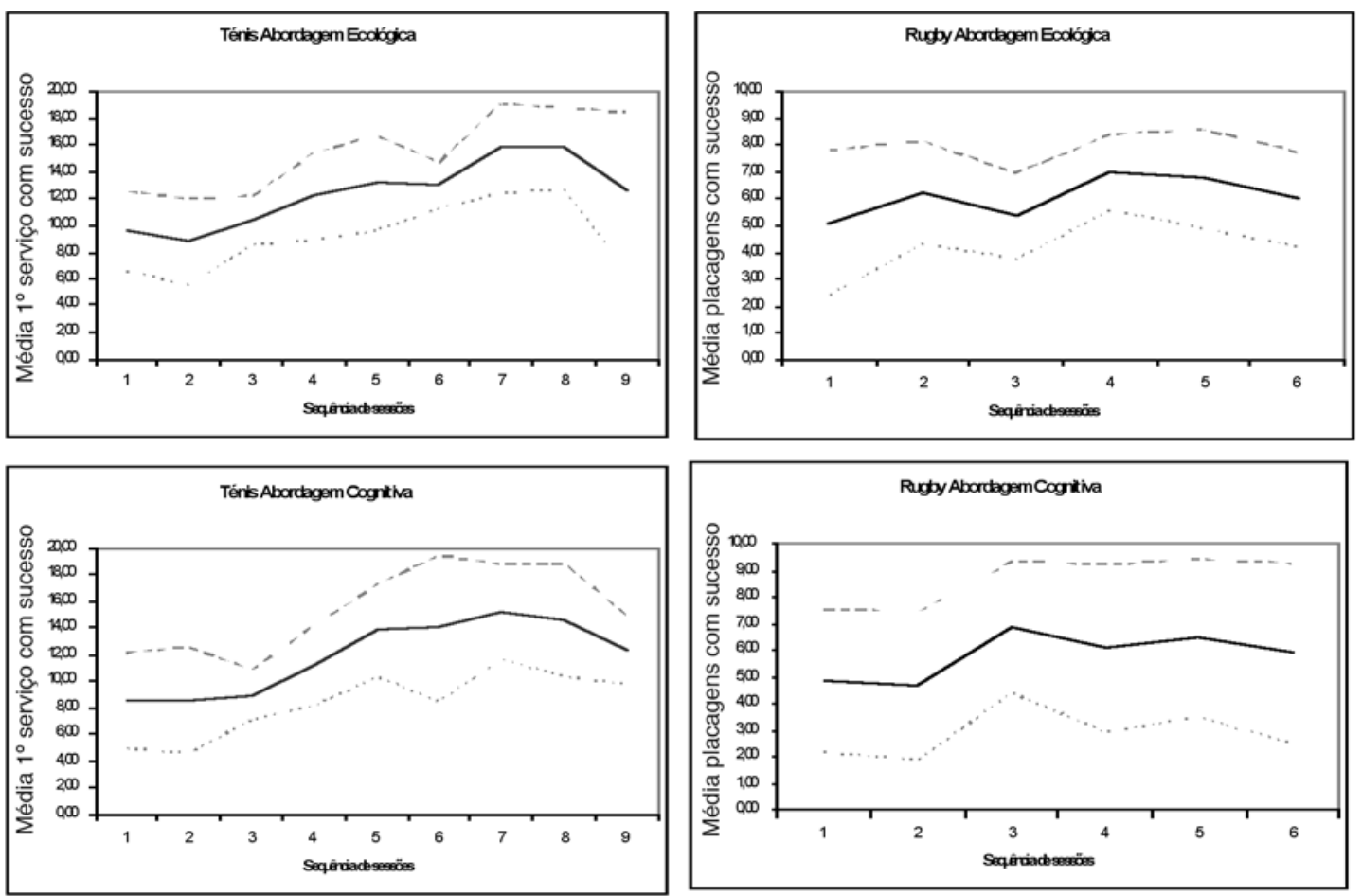

Figura 2. Valores de média e desvio-padrão dos desempenhos com sucesso para o rugby e para o ténis.

Para dar um mai or suporte à análise gráfica, realizámos para ambos os estudos uma análise estatística intra-grupo (i.e. o mesmo grupo em diferentes momentos) recorrendo ao t-test para amostras emparel hadas com o objectivo de observarmos momentos de evolução de dia para dia. Os resultados revelam a existência de um maior número de picos de evolução para o grupo da abordagem ecológica (verificados para o estudo no Rugby) entre a primeira e a segunda sessão $(t(7)=-2,55 ; p=0.03)$ e entre a terceira e a quarta sessão $(t(7)=-3,52$; $\mathrm{p}=0.01$ ), assim como tendências de decréscimo de desempenho ( $\mathrm{t}(4)=2,26 ; p=0.08$ ) para o grupo da abordagem cognitivista entre a oitava e a nona sessão (verificados para o estudo no Ténis).

Para ambos os estudos realizámos uma análise estatística inter-grupo (i.e. comparação entre os dois gru- pos em cada momento) a qual não revela diferenças estatisticamente significativas entre os dois grupos.

Apresentação dos resultados para o Rugby

Pela análise qualitativa do desempenho da placagem, é possível observar que os valores de desvio-padrão apresentam no grupo da abordagem ecológica, uma mai or proximidade em torno da média ao longo das várias sessões de treino.

A análise dos valores mínimos e máximos para o grupo da abordagem cognitivista revela que este grupo apresenta simultaneamente o valor mais (0) baixo e o mais elevado (10) no desempenho da placagem, contribuíndo assim para um desvio-padrão elevado. Facto que pode ser observado na figura 3, onde estão representados exemplos do perfil de desempenho para cada abordagem. 

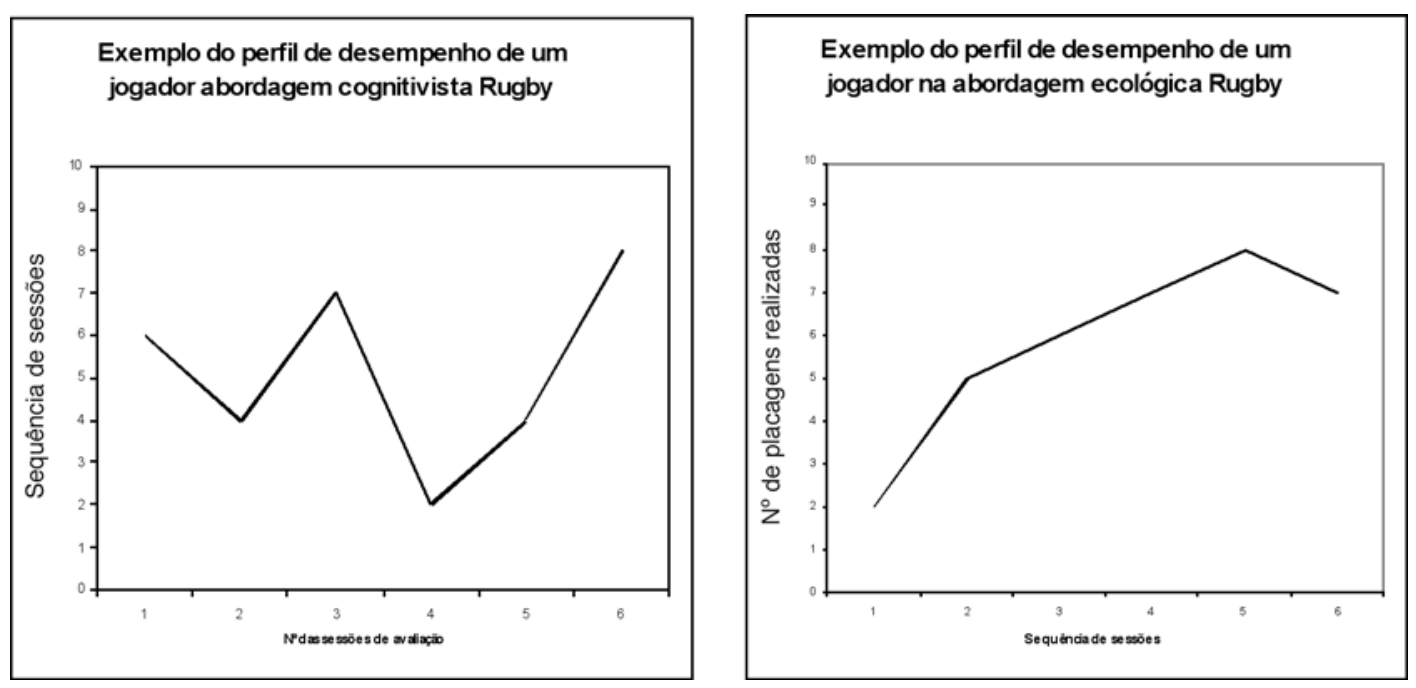

Figura 3. Exemplo do perfil de desempenho entre abordagem ecológica e cognitivista para o Rugby.

Porém através da análise estatística intra-grupo é possivel observar que existem dois picos de evolução de desempenho (entre a $1^{\underline{a}}$ e a $2^{\underline{a}}$ sessão; e entre a $3^{a}$ e a 4a sessão) para o grupo da abordagem ecológica (tabela 1) em que a média de placagens realizadas da $1{ }^{a}$ para a $2^{\underline{a}}$ sessão tem um aumento de $5,13(2,70)$ para $6,15(1,91)$, para da 3a para a 4a sessão ter um aumento de 5,38 $(1,60)$ para $7,00(1,41)$ e apenas um pico de evolução (entre a $2^{\text {a }}$ e a $3^{\text {a }}$ sessão) para o grupo da abordagem cognitivista (tabela 2), em que a média de placagens realizadas teve um aumento de $4,70(2,79)$ para $6,90(2,47)$.

Tabela 1. t-test amostras emparelhadas Rugby abordagem ecológica.

\begin{tabular}{|c|c|c|c|c|c|c|c|}
\hline & & Paired Differences & & & $t$ & $d f$ & Sig. \\
\hline & & Mean & Std. Deviation & Std. Error Mean & & & \\
\hline Par 1 & DIA01 - DIA02 & $-1,13$ & 1,25 &, 44 & $-2,553$ & $?$ & ,038 \\
\hline Par 2 & DIA02 - DIA03 & ,88 & 1,73 & ,61 & 1,433 & $?$ & ,195 \\
\hline Par 3 & DIA03 - DIA04 & $-1,63$ & 1,30 & ,46 & $-3,529$ & $?$ & ,010 \\
\hline Par 4 & DIA04 - DIA05 & ,25 & 1,75 & ,62 &, 403 & $?$ & 699 \\
\hline Par 5 & DIA05 - DIA06 & ,75 & 1,28 & ,45 & 1,655 & $?$ & ,142 \\
\hline
\end{tabular}

Apresentação dos resultados para o Ténis Os resultados da análise de estabilidade nos desempenhos para o Ténis revelam uma tendência semeIhante à do Rugby. Porém na quarta, quinta e nona sessão de avaliação, o grupo da abordagem cognitivista apresenta menores val ores de desvio-padrão. Nas restantes sessões, todos os sujeitos do grupo da abordagem ecológica, apresentam valores mais próximos do máximo. Para além destes resultados, ao observármos os valores das médias, verificamos que é o grupo da abordagem ecológica que apresenta durante mais sessões, médias de desempenho mais próximas dos valores máximos. Facto que pode ser observado na figura 4, onde estão representados exemplos do perfil de desempenho para cada abordagem. 
Tabela 2. t-test amostras emparelhadas Rugby abordagem cognitivista.

\begin{tabular}{|c|c|c|c|c|c|c|c|}
\hline & & Paired Differences & & & $t$ & $d f$ & Sig. \\
\hline & & Mean & Std. Deviation & Std. Error Mean & & & \\
\hline Par 1 & $\begin{array}{l}\text { DIA01 } \\
\text { DIA02 }\end{array}$ & ,20 & 2,82 & ,89 & ,224 & 9 & ,828 \\
\hline Par 2 & $\begin{array}{l}\text { DIA02 - } \\
\text { DIA03 }\end{array}$ & $-2,20$ & 2,57 & ,81 & $-2,703$ & 9 & ,024 \\
\hline Par 3 & $\begin{array}{l}\text { DIA03 - } \\
\text { DIA04 }\end{array}$ & ,80 & 1,93 &, 61 & 1,309 & 9 & ,223 \\
\hline Par 4 & $\begin{array}{l}\text { DIA04 } \\
\text { DIA05 }\end{array}$ &, 40 & 1,58 &, 50 & -802 & 9 & ,443 \\
\hline Par 5 & $\begin{array}{l}\text { DIA05 } \\
\text { DIA06 }\end{array}$ & ,60 & 3,03 & ,96 & ,627 & 9 &, 546 \\
\hline
\end{tabular}
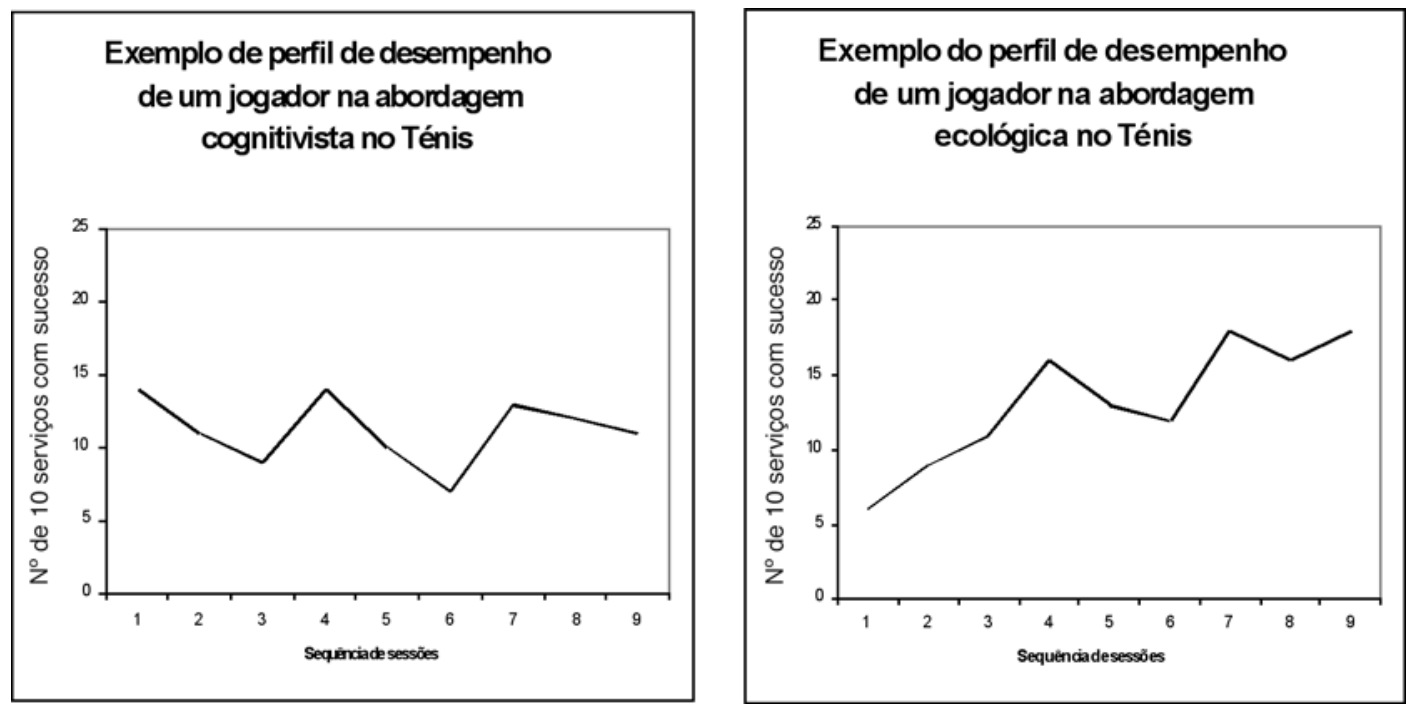

Figura 4. Exemplo do perfil de desempenho entre abordagem ecológica e cognitivista para o Ténis.

Através da análise estatística intra-grupo, é possivel observar que grupo da abordagem ecológica (tabela 3) não apresenta diferenças estatisticamente significativas ao longo das sessões, porém o grupo da abordagem cognitivista (tabela 4), revela uma tendência para um decréscimo de desempenho entre a 8ạ e a última sessão, em que a média de primeiros serviços com sucesso decresce de $14,60(4,22)$ para $12,40(2,61)$. 
Tabela 3. t-test amostras emparelhadas Ténis abordagem ecológica.

\begin{tabular}{|c|c|c|c|c|c|c|c|}
\hline & & Paired Differences & & & $t$ & $d f$ & Sig. \\
\hline & & Mean & Std. Deviation & Std. Error Mean & & & \\
\hline Par 1 & $\begin{array}{l}\text { DIA01 } \\
\text { DIA02 }\end{array}$ & ,80 & 2,49 & 1,11 & , ?18 & 4 &, 512 \\
\hline Par 2 & $\begin{array}{l}\text { DIA02 - } \\
\text { DIA03 }\end{array}$ & $-1,60$ & 3,29 & 1,47 & $-1,089$ & 4 & ,338 \\
\hline Par 3 & $\begin{array}{l}\text { DIA03 - } \\
\text { DIA04 }\end{array}$ & $-1,80$ & 4,44 & 1,98 &,- 907 & 4 & ,416 \\
\hline Par 4 & $\begin{array}{l}\text { DIA04 - } \\
\text { DIA05 }\end{array}$ & $-1,00$ & 5,43 & 2,43 &,- 412 & 4 & ?02 \\
\hline Par 5 & $\begin{array}{l}\text { DIA05 } \\
\text { DIA06 }\end{array}$ & ,20 & 3,70 & 1,66 & ,121 & 4 & ,910 \\
\hline Par 6 & $\begin{array}{l}\text { DIA06 - } \\
\text { DIA0? }\end{array}$ & $-2,80$ & 3,03 & 1,36 & $-2,064$ & 4 & 108 \\
\hline Par? & $\begin{array}{l}\text { DIA0? } \\
\text { DIA08 }\end{array}$ &, 00 & 2,35 & 1,05 &, 000 & 4 & 1,000 \\
\hline Par 8 & $\begin{array}{l}\text { DIA08 - } \\
\text { DIA09 }\end{array}$ & 3,20 & 4,38 & 1,96 & 1,633 & 4 & , 178 \\
\hline
\end{tabular}

Tabela 4. t-test amostras emparelhadas Ténis abordagem cognitivista.

\begin{tabular}{|c|c|c|c|c|c|c|c|}
\hline & & Paired Differences & & & $t$ & $d f$ & Sig. (2-tailed) \\
\hline & & Mean & Std. Deviation & Std. Error Mean & & & \\
\hline Par 1 & $\begin{array}{l}\text { DIA01 - } \\
\text { DIA02 }\end{array}$ &, 00 & 2,55 & 1,14 &, 000 & 4 & 1,000 \\
\hline Par 2 & $\begin{array}{l}\text { DIA02 - } \\
\text { DIA03 }\end{array}$ & , 40 & 2,70 & 1,21 &,- 331 & 4 & , $75 ?$ \\
\hline Par 3 & $\begin{array}{l}\text { DIA03 - } \\
\text { DIA04 }\end{array}$ & $-2,20$ & 2,59 & 1,16 & $-1,901$ & 4 & 130 \\
\hline Par 4 & $\begin{array}{l}\text { DIA04 - } \\
\text { DIA05 }\end{array}$ & $-2,60$ & 5,18 & 2,32 & $-1,123$ & 4 & ,324 \\
\hline Par 5 & $\begin{array}{l}\text { DIA05 - } \\
\text { DIA06 }\end{array}$ &,- 20 & 3,11 & 1,39 &,- 144 & 4 & ,893 \\
\hline Par 6 & $\begin{array}{l}\text { DIA06 - } \\
\text { DIA0? }\end{array}$ & $-1,20$ & 3,11 & 1,39 &,- 862 & 4 & ,438 \\
\hline Par? & $\begin{array}{l}\text { DIA0? - } \\
\text { DIA08 }\end{array}$ &, 60 & 1,52 & ,68 & ,885 & 4 & ,426 \\
\hline Par 8 & $\begin{array}{l}\text { DIA08 - } \\
\text { DIA09 }\end{array}$ & 2,20 & 2,17 & ,97 & 2,269 & 4 & ,086 \\
\hline
\end{tabular}




\section{DISCUSSÃO}

No estudo realizado no Rugby e pelos valores de desvio-padrão sugerimos que o grupo da abordagem ecológica revelou uma maior estabilidade na realização da placagem. O que significa que os jogadores deste grupo, tinham em cada momento de avaliação, uma frequência de placagens de sucesso próximos uns dos outros. Estes resultados podem ser justificados pelo facto da metodologia aplicada promover uma aprendizagem em que as soluções encontradas pelo jogador são mais ajustadas às suas características e consequentemente, mais consistentes ao longo do tempo.

Por outro lado, o facto de no grupo da abordagem cognitiva para o mesmo momento de avaliação, haver sujeitos com desempenhos próximos dos valores máximos e sujeitos com desempenhos próximos dos valores mínimos, significa que uma abordagem cognitiva para o treino da placagem, ao dirigir o sistema para padrões motores pré-definidos, está a adoptar uma metodologia que elimina as várias hipóteses de acção que poderiam ser mais adequadas a alguns dos jogadores (4). O modelo de execução prescrito tanto pode promover um desempenho totalmente desajustado às características do sujeito, não permitindo que este atinja o seu objectivo uma única vez, como pode promover um desempenho totalmente ajustado, isto é, permitindo que o defesa consiga atingir sempre o seu objectivo. Estas diferenças na estabilidade de desempenho podem ser fortalecidas pela análise intra-grupo, onde o grupo da abordagem ecológica apresenta dois momentos de evolução significativa nos desempenhos da placagem (i.e. entre a 1a e a 2a sessão e entre a 3a e a 4ํa sessão) enquanto que o grupo da abordagem cognitivista um único momento de evolução (i.e. entre a $2^{a}$ e a 3ạ sessão). Poderemos então sugerir que o treino assente na manipulação de constrangimentos (abordagem ecológica), promovendo uma exploração activa do melhor caminho atingir um objectivo (i.e. placar) conduz a uma maior estabilidade de desempenho a qual se traduz em monentos de evolução significativa do desempenho.

Em relação ao Ténis o grupo da abordagem cognitivista apenas em três sessões de avaliação (4a, 5a e 9a) apresentou menores valores de desvio-padrão em relação ao grupo da abordagem ecológica, o que sig- nifica que apenas nestas três sessões é que teve uma maior estabilidade no número de primeiros serviços com sucesso. Porém, se nos sustentarmos na análise intra-grupo, e em oposição ao que verificamos para o Rugby, no estudo do Ténis a estabilidade não se traduz numa evolução de desempenho, antes pelo contrário, pois o grupo da abordagem cognitivista revela uma tendência para que exista um decréscimo no número de primeiros serviços com sucesso.

Por último, os resultados da comparação inter-grupo que revelam a não existência de diferenças significativas entre os dois grupos em qualquer momento para as duas modalidades, suscita uma interpretação diferente da abordagem cognitivista, assim poderemos sugerir que o carácter normativo e prescritivo desta abordagem, acaba por ser diluído no carácter ecológico da treino, pois a forma activa como o atleta explora o envolvimento para alcançar um objectivo será sempre altamente específica, individualizada e sustentada pela dinâmica dos acoplamentos de percepção-acção.

Os resultados obtidos parecem indicar que a manipulação de constrangimentos de tarefa (abordagem ecológica), com o objectivo de conduzir o sujeito para o desempenho desejado, se revela uma metodologia mais eficaz do que a prescrição de determinado tipo de movimentos com a utilização do feedback como fonte de instrução para manter o jogador na procura do modelo ideal de execução.

\section{CONCLUSÕES}

Quer para o Rugby como para o Ténis, constatou-se que o grupo da abordagem ecológica, em que o treino assenta numa manipulação dos constrangimentos, é aquele que apresentou durante mais tempo e com maior frequência desempenhos próximos do seu melhor.

Conduzir o treino para a procura dos modelos ideais de execução, leva a que os atletas tenham maiores oscilações entre bons e maus desempenhos.

\section{SUGESTÕES PARA O TREINO}

A abordagem ao treino com base nos pressupostos da Psicologia Ecológica levanta-nos uma questão em relação à pertinência de utilização de dois pilares da intervenção pedagógica do treinador: i) a frequência do feedback e ii) a razão da demonstração. Em relação 
ao primeiro concordamos com outros autores (4), a informação de retorno aumentada verbal (feedback), não deverá ser frequente, devendo os seus objectivos estar limitados a i) reforçar o objectivo ou as condições de real ização da tarefa, por exemplo, relembrar ao tenista a zona onde a bola tem de ser colocada (objectivo e constrangimento de tarefa), ou relembrar ao jogador de Rugby que a placagem deve ser realizada entre a linha da cintura e os joel hos (constrangimento de tarefa) e ii) ter intenções pedagógicas (motivar, dar confiança, etc). Isto significa que a informação presente no envolvimento deverá ser suficientemente abundante e rica para influenciar a aprendizagem. Logo, a intervenção deverá basear-se na mani pulação dos constrangimentos, isto é, na utilização de metodologias que provoquem alterações nos acoplamentos de percepção-acção que conduzam à auto-organização, a qual faz emergir os comportamentos de sucesso. Quanto à demonstração, ao serem contestados os modelos ideais de execução, a demonstração será útil como forma de ligação entre a acção e o cumprimento da tarefa, podendo servir também para sugerir um padrão motor geral. Então o que devemos procurar com o treino é o que Schonborn sugere em termos biomecânicos como as características de um golpe ideal : simples, económico e eficaz (10). Tudo o resto assenta na interpretação individual, que resulta da exploração que cada atleta faz em relação aos constrangimentos do seu organismo, da tarefa e do envolvimento, numa acção direccionada para um objectivo.

O pressuposto que a informação necessária para a acção se encontrar disponível no envolvimento sendo percepcionada de forma directa pelo sujeito, sugere que existe uma relação directa entre as acções motoras e as circunstâncias do envolvimento. Se entendermos a técnica como uma acção coordenada para dar resposta a um problema táctico, o qual por sua vez resulta das circunstâncias do envolvimento, verificamos que a técnica assenta numa enorme variabilidade que resulta da constante alteração das circunstâncias do envolvimento. Daí que estamos de acordo com estudos anteriores $(4,11)$ ao sugerir a não existência de modelos ideais de execução de um gesto técnico. Então, de forma a adaptar as características de cada atleta à situação, o treino deve assentar na manipulação dos constrangimentos, mais do que na procura de um modelo ideal de execução. Para tal sugerimos o seguinte:

i) identificar para cada situação quais os constrangimentos de tarefa que estão presentes em situação de competição, por exemplo, quais as regras para realizar uma placagem, quais as dimensões do espaço em que normal mente acontecem as situações de $1 \times 1$, qual a altura da rede no serviço no Ténis, quantos adversários vão estar a fazer oposição;

ii) propor no treino exercícios com os mesmos constrangimentos que estão presentes em situação de competição. O facto de disponibilizarmos no treino a mesma informação que está presente em competição, criamos condições para que, por um lado, os atletas aprendam para onde direccionar a sua atenção, e por outro lado, a afinem os acoplamentos de percepção com a aç̧ão, permitindo que sejam cada vez mais selectivos em relação à informação utilizar. Percepcionamos para recolher a informação que nos permite agir, e as nossas acções real izam-se para continuarmos a percepcionar qual a via mais eficaz de mantermos um comportamento para um objectivo. Dito por outras palavras, um defesa no Rugby percepciona um conjunto de variáveis (i.e. qual a velocidade, ângulo de aproximação, e aceleração com que $o$ atacante se aproxima) que Ihe permite antecipar para onde o atacante se está a dirigir, em função desta informação o defesa age, avança em direcção ao atacante, colocando-se numa posição no campo (com o objectivo de interceptar o atacante com uma placagem), essa acção permite ao defesa continuar a percepcionar se $o$ atacante mantém a mesma linha de corrida, ou se por outro lado a altera, este ciclo entre percepção e acção é continuamente alimentado pela acção dos dois jogadores, terminando quando um deles al cança o seu objectivo.

\section{CORRESPONDÊNCIA}

\section{Pedro José Madaleno Passos}

Rua Josefa Galbis Diniz, № 153, 2o Dto, Arneiro

2775-522 Carcavelos

Portugal

p.passos@ clix.pt 


\section{BIBLIOGRAFIA}

1. Davids K, Williams M, Button C, Court M. (1999). An Integrative Modeling Approach to the Study of Intentional Movement Behaviour, 144-168.

2. Abernethy B, Kippers V, MacKinnon LT, Neal RJ, Hanrahan S (1997). The Biophysical Foundations of Human M ovement. Human Kinetics.

3. Williams AM, Grant A (1999). Training perceptual skill in sport. International Journal of Sport Psychology 30:194-220.

4. Machado N, Araújo D, Godinho M (2005). A abordagem dinâmica na aprendizagem do ténis. In D. Araújo (Ed.) 0 contexto da decisão. Lisboa: Visão e contextos, 261-276.

5. Gibson JJ (1979). An Ecological A pproach to Visual Perception. Boston, MA: Houghton-Mifflin.

6. Araújo D (2005). O Contexto da Decisão. A acção táctica no desporto. Visão e Contextos.
7. Araújo D, Davids K, Rocha L, Serpa S, Fernandes O (2003). Decision making in sport as phase transitions. International Journal of Computer Science in Sport 2(2): 87-88.

8. Newell KM (1986), Constraints on the Development of Coordination. In M. Wade and H.T.A. Whiting (Eds.) $M$ otor D evelopment in Children: A spects of Coordination and Control, Dordrecht: Martinus Nijhoff, 341-360.

9. Larder P (1999/2000) Defence - Principles and Practice. Rugby Football Union Technical Journal, Winter, p.15-30.

10 Schonborn R (2002). Los Aspectos más Importantes de la Técnica Moderna y cómo Desarrollarlos. ITF. Coaching \& Sport Science Review , 3 - 5.

11. Passos Araújo, Davids Gouveia, Serpa (in press). Interpersonal Dynamics in Sport: The Role of Artificial Neural Networks and Three-dimensional Analysis. Behavior and Research Methods. 